Research Article

\title{
Extending the Utility of UTAUT2 for Hospital Patients' Adoption of Medical Apps: Moderating Effects of e-Health Literacy
}

\author{
Yung-Tzung Chang, ${ }^{1}$ Cheng-Min Chao ${ }^{D},{ }^{2}$ Chen-Wei Yu, ${ }^{1}$ and Fang-Chen Lin ${ }^{3}$ \\ ${ }^{1}$ Department of Family Medicine, Taoyuan Armed Force General Hospital, Taoyuan, Taiwan \\ ${ }^{2}$ Department of Business Administration, National Taichung University of Science and Technology, Taichung, Taiwan \\ ${ }^{3}$ Department of Health and Leisure Management, Hsin Sheng Junior College of Medicine Care and Management, \\ Taoyuan, Taiwan \\ Correspondence should be addressed to Cheng-Min Chao; g9521807@gmail.com
}

Received 25 March 2020; Revised 25 March 2021; Accepted 27 March 2021; Published 12 April 2021

Academic Editor: Daniele Riboni

Copyright (c) 2021 Yung-Tzung Chang et al. This is an open access article distributed under the Creative Commons Attribution License, which permits unrestricted use, distribution, and reproduction in any medium, provided the original work is properly cited.

\begin{abstract}
Hospitals have begun to provide their own apps to improve the efficiency of hospital services. This study investigated the factors influencing the adoption of medical apps by hospital patients by using a theoretical model that combines the extended unified theory of acceptance and use of technology (UTAUT) with the concept of e-health literacy and personal innovativeness (PI). Data were obtained from responses to a paper-based self-reported questionnaire issued to patients at a hospital in Taoyuan, Taiwan. Of the 650 distributed questionnaires, we received 629 completed questionnaires, yielding a response rate of $96.8 \%$. The responses to the completed questionnaires were analyzed using structural equation modeling (SEM). Partial least squares regression was used for model and hypothesis testing. The data were analyzed using an SEM approach to test ten hypotheses; significant support was observed for five of these hypotheses. The results indicated that habit, performance expectancy, facilitating conditions, and PI had significant positive effects on the usage intention (UI) of individuals, thereby confirming that e-health literacy moderates the association between performance expectancy and UI. This research contributes to the current understanding of adoption of hospital medical apps by patients. The findings are expected to assist hospitals in deciding whether to consider medical apps when investing in information technology.
\end{abstract}

\section{Introduction}

With the progress of technology and popularity of the Internet, information technologies (ITs) such as messaging and communications technology, Internet technologies, and computers have become integrated into people's daily lives and have enhanced economic and social progress. Because of the popularization of mobile computing, numerous people possess smartphones, tablets, or laptop computers, and other mobile devices; such devices enable users to access the Internet and use information and communications technologies (ICTs) at any time. ICTs provide several advantages to organizations and users. In hospitals, the Internet, ITs, and information systems (ISs) are increasingly used to facilitate health-care management.
Smart home and health-care systems also use these technologies [1-3].

As the number of consumers who use smartphones and tablet computers has increased, people's daily lives have become more convenient [4]. The popularization of mobile commerce has enabled users to acquire information online to satisfy the various demands of daily life [5]. Thus, consumers are increasingly dependent on mobile devices [6], and this has prompted the rapid development of smartphone applications or "apps" [7]. Hospitals have paid considerable attention to app usage. Hospitals use apps to assist with services such as patient registration, outpatient service progress, promoting health education, and outpatient schedules. By using apps, hospitals aim to increase public satisfaction and reduce registration waiting times. 
Several theories have discussed the usage intention (UI) of users toward new technologies. These theories include the theory of reasoned action (TRA), theory of planned behavior (TPB), technology acceptance model (TAM), and unified theory of acceptance and use of technology (UTAUT) $[8,9]$. Venkatesh et al. [10] combined the TRA, TPB, TAM, motivational model, social cognitive theory, model of PC utilization, combined TAM and TPB model, and innovation diffusion theory. The researchers deduced that the UTAUT model explained up to $70 \%$ of users' behaviors; this was considerably higher than the results of previous models. Thus, this model was considered to explain user behavior more completely. Venkatesh et al. [11] developed an extended UTAUT (UTAUT2) model. The UTAUT2 model is currently the most comprehensive model and was derived by extending the UTAUT model. Venkatesh et al. [11] argued that the UTAUT2 is suitable for analyzing consumer behavior.

In recent years, the UTAUT2 model has been acknowledged as one of the latest theoretical frameworks to explore the users' adoption and acceptance of new technologies and has been increasingly given attention from researchers. In addition, the model has been widely used in different industries and domain, including air travel market, mobile banking, social media websites, mHealth services, and social networks sites [12-18]. For example, Alam et al. [12] proposed a comprehensive conceptual model that investigates the determinants of the adoption intention and use of mHealth services in a developing country. The model was based on the extended UTAUT2 and other factors. The results confirmed that performance expectancy, social influence, facilitating conditions, and perceived reliability positively influence behavioral intention (BI). The model proposed by Alalwan et al. [13] expands the UTAUT2, to explore the factors that influence the adoption of mobile banking by Jordanian bank customers. The results indicated that performance expectation, effort expectancy, hedonic motivation, price value, and trust have a significant and positive impact on BI. Macedo [15] confirms that, in the UTAUT2 model, performance expectancy, effort expectancy, social influence, facilitating conditions, hedonic motivation, and habit have a significant positive impact on older adults' BI to use ICT; among them, performance expectancy had the greatest impact. Habits have a significant positive impact on use behavior. Sheikh et al. [16] developed an extended UTAUT 2 model incorporating social support, social commerce constructs, and cultural moderators to investigate the factors affecting social commerce acceptance. The results indicated that performance expectancy, habit, hedonic motivation, social commerce construct, social support, and price-saving orientation have a positive association with BI. Escobar-Rodríguez and Carvajal-Trujillo [17] used the UTAUT2 model that was proposed by Venkatesh et al. [11]. The results showed that performance expectation, effort expectation, social influence, facilitating conditions, hedonic motivation, habits, and price-saving orientation have positively affected the online purchase intention. Based on the above discussion, in the theoretical framework of UTAUT2, many researchers indicated that performance expectation, effort expectation, social influence, facilitating conditions, hedonic motivation, habits, and price value have an impact on BI.

The concept of innovativeness was first proposed by Rogers and Shoemaker [18], who argued that innovativeness refers to the degree to which an individual adopts innovative ideas earlier than others in the same social system $[19,20]$. Agarwal and Prasad [21] defined personal innovativeness (PI) from the perspective of IT as an individual's willingness to try new ITs. This type of PI is an inherent characteristic and affects an individual's attitude toward new products [22, 23]. Limayern et al. [24] defined innovativeness as the degree to which an individual uses a new technology earlier than others in the same social system. Innovativeness can affect other consumers' usage behaviors through their attitude and intention. In a study by Wong et al. [25], they adopted the UTAUT as a basic model and combined it with personal innovativeness in information technology (PIIT), perceived enjoyment (PEJ), and mobile skillfulness (MS) to explore factors that influence consumers' BI to use $\mathrm{m}$-advertising. They found that performance expectation, effort expectation, social influence, and facilitating conditions have an impact on BI. However, personal PIIT has no effect on BI. However, some previous researchers have proven that PIIT has an impact on the adoption of new technologies [26, 27].

Following the rapid development of the Internet and its integration into everyday life, people use it to search for information, communicate, perform recreational activities, and work [28-30]. Online medical health information often includes professional terminology, complex health-care information, and misleading information [31]. This reflects insufficiencies in the public's health literacy, health information literacy, and e-health literacy. In recent years, governments worldwide have actively promoted e-health. For instance, Norman and Skinner [32] raised the importance of e-health literacy, which lies primarily in assisting consumers with using IT to promote health and medical care. Such assistance has enabled e-health literacy to gain increasing attention. When social and technical issues affect computer-based conflicts, literacy becomes more complex. To fully utilize IT to promote health, special techniques and abilities are required in addition to literacy [33]. Norman [33] stated that the skill of combining e-health literacy with various qualities can be applied for the promotion and care of e-health. These qualities include the core literacies (or skills) of traditional literacy, information literacy, computer literacy, media literacy, scientific literacy, and health literacy. The present study defined e-health literacy as the ability of the public to operate apps and use them to acquire, search for, and evaluate or create information, in order to promote and maintain their personal health.

In summary, medical apps are gaining increasing attention in hospitals and are used for services such as assisting with patient registration, requests for information on outpatient service progress, and promotion of health education. Such usage increases public satisfaction and reduces registration waiting times. In the past, many theories such as the TRA, TPB, TAM, and UTAUT have examined the adoption 
intention of users toward new ITs and ISs. Among these theories, the TPB and TAM are the most influential and widely used $[34,35]$. However, regarding predictions of UI, the TAM considers only the variables of perceived ease of use and perceived usefulness and explains only approximately $40 \%$ of variation in UI. The UTAUT provides a more comprehensive explanation, with the explained variance approaching $70 \%$ [10]. Venkatesh et al. [11] further proposed the UTAUT2 model and argued that this model was suitable for analyzing the usage behaviors of individuals toward new ITs and ISs. Therefore, the current study employed UTAUT2 as a base model and combined it with PI to examine the UIs of residents of Taoyuan, Taiwan, toward medical apps. However, the application of UTAUT2 model in this study faced limitations. The hedonic motivation means "the pleasure or enjoyment derived from using technology" [16]; price value means the value of the perceived benefit from the technology compared to the cost. Due to the fact that the medical app in this study is developed by the hospital, it is available to the public to download for free. Its function is mainly based on medical services, and there are no other interesting functions. Therefore, hedonic motivation and price value could not be included in the research model. In addition, to investigate whether the e-health literacy of individuals influenced their UIs toward medical apps, e-health literacy was included as a moderating variable. The empirical findings of this study are provided as a reference for hospitals and businesspeople engaged in developing medical apps, seeking medical health information, and related strategies.

\section{Research Methodology}

2.1. Research Model. The hypothesized model was constructed using the exogenous variables of habit, performance expectancy (PE), effort expectancy (EE), social influence (SI), facilitating conditions (FCs), and PI; the endogenous variable of UI; and the moderating variable of e-health literacy (see Figure 1). The hypotheses, discussed in subsequent sections, are numbered and illustrated in the proposed path model.

\subsection{Research Hypotheses}

Hypothesis 1. Habit has a significant effect on UI.

Hypothesis 2. PE has a significant effect on UI.

Hypothesis 3. EE has a significant effect on UI.

Hypothesis 4. SI has a significant effect on UI.

Hypothesis 5. FCs have a significant effect on UI.

Hypothesis 6. PI has a significant effect on UI.

M1: the relationship between PE and UI is moderated by the level of e-health literacy

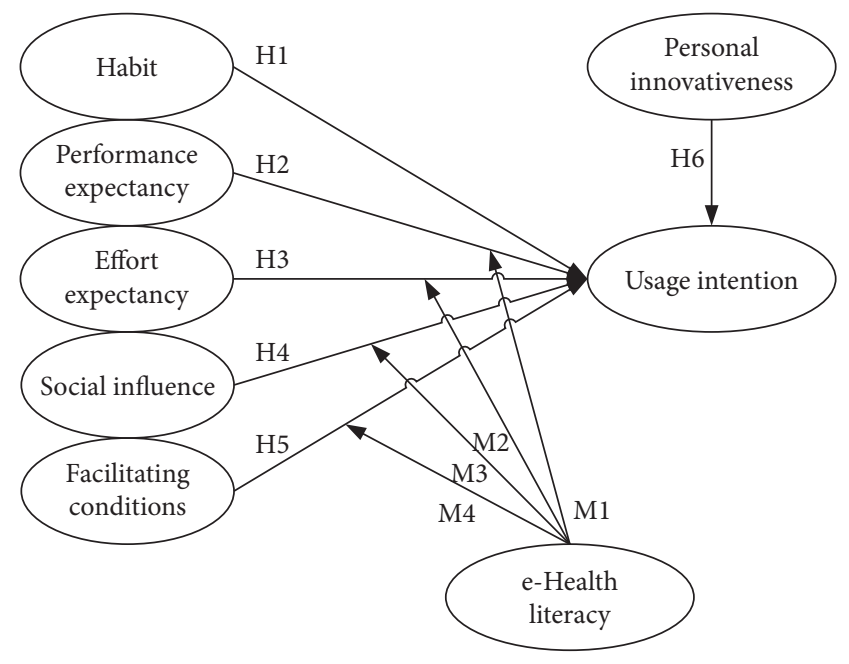

FIgURE 1: Research framework.

M2: the relationship between EE and UI is moderated by the level of e-health literacy

M3: the relationship between SI and UI is moderated by the level of e-health literacy

M4: the relationship between FC and UI is moderated by the level of e-health literacy

2.3. Instrumentation. Data were collected using a two-part questionnaire survey. The first part examined the respondents in relation to the UTAUT and assessed their PE, EE, SI, FCs, UI, PI, and e-health literacy by using a 5-point Likert scale with values ranging from 1 (strongly disagree) to 5 (strongly agree). The second part used a nominal scale to obtain basic information about the respondents' characteristics, including their gender, age, formal education, monthly income, and intention to use the medical app system.

Our scale was developed following the recommendations of MacKenzieet al. [36] and the standard psychometric scale development procedures suggested by Devellis [37]. We translated measuring items for UTAUT2 constructs (25 items) developed by previous researchers $[11,14-16,19]$ into traditional Chinese. The measuring items for UTAUT2 constructs included habit (three items), PE (five items), EE (five items), SI (four items), FCs (four items), and UI (four items). The measuring items of PI constructs were adapted from a measurement developed by previous researchers $[18,20,21,25-27]$ and contained five items. Nine items were included for e-health literacy $[32,33]$. Details on the questionnaire used are shown in Table 1.

To ensure that the survey questions were concise and understandable, in-depth interviews and a pilot study were conducted. The questionnaires were initially administered to seven researchers who specialized or were interested in hospital management, IT and management, ISs, and medical app systems. The research procedure was reviewed and approved by the Institutional Review Boards (IRB) of TriService General Hospital (2-105-05-144). Convenience 
TABLE 1: Measurement items.

\begin{tabular}{ll}
\hline Constructs/items & Sources
\end{tabular}

Habit

(1) Using medical apps has become a habit of mine

(2) I believe that medical apps have become important tools in my life

(3) Using medical apps comes naturally to me

Performance expectancy (PE)

(1) Medical apps are helpful in my daily life

(2) Using medical apps can satisfy my medical health-care needs

(3) Using medical apps can improve my efficiency in monitoring health conditions

(4) Using medical apps can improve my health management ability

(5) Using medical apps can improve the monitoring of my health conditions

Effort expectancy (EE)

(1) Learning to use medical apps is very simple for me

(2) The interactions with medical apps are clear and easy to understand

(3) The operations of medical apps are simple and convenient

(4) Medical apps are easy to use

(5) I can easily master the skills of using medical apps Social influence (SI)

(1) People who are important to me believe that I should use medical apps

(2) People who influence my behavior believe that I should use medical apps

(3) People whose opinions I value prefer using medical apps

(4) People whom I trust believe that I should use medical apps Facilitating conditions (FCs)

(1) I have the necessary resources for using medical apps

(2) I have the necessary knowledge and skills for using medical apps

(3) The medical apps that I am using are compatible with other technologies

(4) When I have difficulties using medical apps, I can obtain help from other people

Usage intention (UI)

(1) I intend to continue using medical apps in the future

(2) I will try using medical apps in my daily life

(3) I am planning to use medical apps often

(4) Overall, I am willing to continue using medical apps

Personal innovativeness (PI)

(1) When a new technology product or service emerges, I am usually the first among my friends to know about it

(2) In the fields in which I am interested, I can always keep up with the developments of the latest technologies

(3) if I hear about a new information technology, I look for ways to experiment with it

(4) I like to experiment with new information technologies (ITs)

(5) When using technologies, I encounter fewer problems than others

Venkatesh et al. [11], Herrero eta 1. [14], Macedo [15], Sheikh et al. [16], Escobar-Rodríguez and Carvajal-Trujillo [17], and Alam et al. [19]

Rogers and Shoemaker [18], Rogers [20], Agarwal, and Prasad [21], Wong et al. [25], Tan et al. [26], and Al-Busaidi [27] 
TABLE 1: Continued.

\begin{tabular}{l}
\hline Constructs/items \\
\hline e-Health literacy \\
(1) I know what health resources are available on the Internet \\
(2) I know where to find helpful health resources on the Internet \\
(3) I know how to find helpful health resources on the Internet \\
(4) I know how to use the Internet to obtain answers to my \\
questions about health \\
(5) I know how to use health information on the Internet to help \\
me \\
(6) I can rate the health resources on the Internet \\
(7) I can distinguish between high- and low-quality health \\
resources on the Internet \\
(8) I can determine the correctness of health information on the \\
Internet \\
(9) I feel confident in using information from the Internet to \\
make health decisions
\end{tabular}

sampling was used to issue 250 questionnaires to medical app users in Taoyuan, Taiwan. After excluding 54 invalid questionnaires, the same questionnaire was administered to 196 hospital patients experienced in using medical apps. Regarding the reliability of all constructs, Cronbach's alpha coefficients ranged from 0.824 for habit to 0.959 for UI, both of which were substantially higher than the minimum value of 0.7 that is considered acceptable as an indication of reliability [38]. These results implied that the scales used in this research satisfactorily measured the constructs of interest. Based on the pilot study results, the questionnaire was revised twice. The final questionnaire comprised 46 items in addition to a series of demographic and self-reported usage items.

2.4. Sample and Descriptive Statistics. We issued the questionnaires during face-to-face interviews with patients at a hospital in Taoyuan, Taiwan. The participants in this study were volunteers. We distributed 650 questionnaires to users of the medical app system selected through convenience sampling. All 650 questionnaires were returned; however, 21 responses where at least onethird of the items were unanswered or incompletely answered were discarded. The remaining 629 valid responses (effective retrieval rate: $96.8 \%$ ) were statistically analyzed. The general characteristics of the participants are listed in Table 2. In the survey, the percentages of men and women were $46.1 \%$ and $53.9 \%$, respectively; most of the participants were aged $\leqq 49$ years $(66.7 \%), 56.4 \%$ had attended college and university, and the most prevalent monthly income bracket was NT\$20,001-40,000 (44.5\%). The overall intention to use the medical app system was willing $(42.3 \%)$.

\section{Results}

We combined the analyses of measurement and structural models through structural equation modeling (SEM). The most common SEM techniques include linear structural relationship and partial least squares (PLS) $[39,40]$. The PLS technique is component-based and involves a least squares
TABle 2: Profiles of respondents $(N=692)$.

\begin{tabular}{lcc}
\hline Factor/level & $N$ & $\%$ \\
\hline Gender & & \\
$\quad$ Male & 290 & 46.1 \\
Female & 339 & 53.9 \\
Age & & \\
$\leq 49$ & 420 & 66.7 \\
$50-59$ & 102 & 16.3 \\
60-69 & 80 & 12.7 \\
\70 & 27 & 4.3 \\
Formal education & & \\
Elementary school and below & 22 & 3.5 \\
Junior high school & 38 & 6.0 \\
Senior/vocational high school & 138 & 21.9 \\
College and university & 355 & 56.4 \\
Graduate institute and above & 76 & 12.1 \\
Monthly income & & \\
$\quad<20,000$ & 121 & 19.2 \\
20,001-40,000 & 280 & 44.5 \\
40,001-60,000 & 154 & 24.5 \\
60,001-80,000 & 40 & 6.4 \\
80,001-100,000 & 22 & 3.5 \\
$\quad>100,001$ & 12 & 1.9 \\
Intention to use the medical app system & & \\
Highly willing & 166 & 26.4 \\
Willing & 266 & 42.3 \\
Neutral & 166 & 26.4 \\
Unwilling & 27 & 4.3 \\
Highly unwilling & 4 & 0.6 \\
\hline
\end{tabular}

estimation procedure. PLS can be used to determine construct and structural validities and can be used to analyze measurement and structural models.

Depiction of a research model containing moderators with PLS differs from the traditional representation of the said model. In a PLS model, the moderator (e-health literacy in the present construct) is depicted as an independent variable with a direct path to UI. According to Chin et al. [41], these interaction measurement variables are calculated by multiplying every indicator in the moderator by every indicator in the independent variable. Conceptually, the interaction construct $(\mathrm{PE} \times \mathrm{e}$-health literacy, $\mathrm{EE} \times \mathrm{e}$-health 
TABLE 3: Validity and reliability.

\begin{tabular}{lcccrrr}
\hline Construct & Mean & SD & Cronbach's alpha & AVE & CR & DV \\
\hline Habit & 3.61 & 0.78 & 0.903 & 0.775 & 0.932 & 1.254 \\
Performance expectancy (PE) & 4.01 & 0.67 & 0.932 & 0.788 & 0.949 \\
Effort expectancy (EE) & 3.88 & 0.71 & 0.942 & 0.777 & 0.954 \\
Social influence (SI) & 3.59 & 0.80 & 0.951 & 0.872 & 0.965 \\
Facilitating conditions (FCs) & 3.75 & 0.72 & 0.888 & 0.753 & 0.924 \\
e-Health literacy & 3.88 & 0.56 & 0.896 & 0.545 & 0.915 \\
Personal innovativeness (PI) & 3.70 & 0.72 & 0.920 & 0.757 & 0.939 \\
Usage intention (UI) & 3.91 & 0.74 & 0.948 & 0.864 & 0.962 & 2.289 \\
\hline
\end{tabular}

AVE: average variance extracted, CR: composite reliability, and DV: discriminant validity.

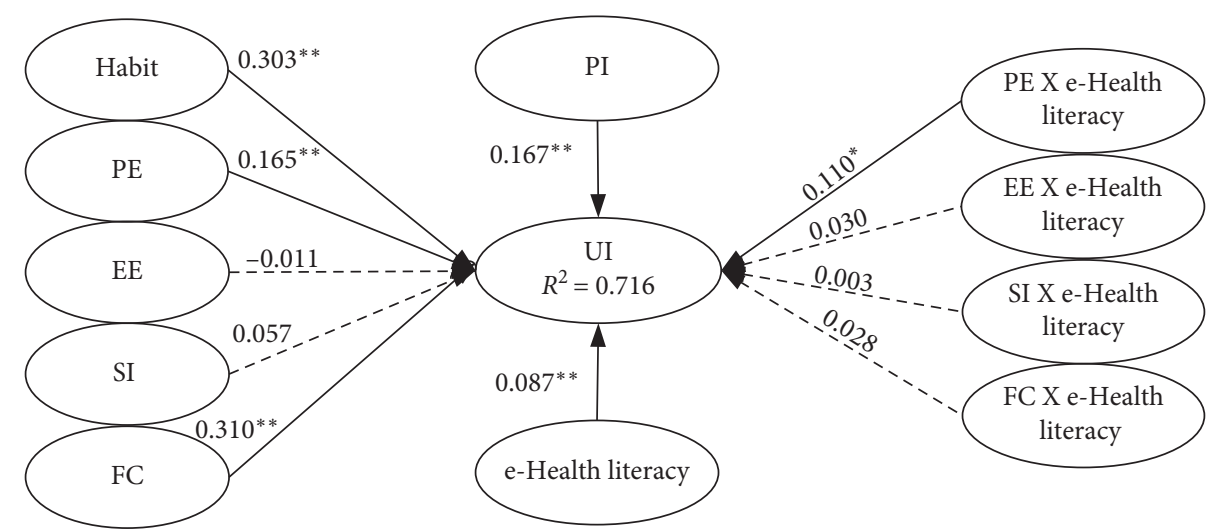

FIGURE 2: Path coefficients for the research model (including interaction effect). Value on path: standardized coefficients $(\beta), R^{2}:$ coefficient of determination, and ${ }^{*}, p<0.01 ;{ }^{*}, p<0.05$.

literacy, SI $\times$ e-health literacy, and FCs $\times$ e-health literacy) is depicted as having a direct path to BI. This study used PLS to analyze the research model.

This study has applied Harman's one-factor test to confirm the existence of common method variance (CMV) in the resultant data set [42]. The result indicated that the first factor accounts for $46.73 \%$ of the variance and meets the criterion that the first fixed factor must explain less than 50\% of the variance, implying that no CMV occurred [42].

3.1. Measurement Model Evaluation. The relationship between the observed variables (i.e., manifest variables or indicators) and latent variables (i.e., constructs being measured) were specified using the measurement model. The convergent and discriminant validity of each construct was evaluated to verify the suitability of the construct measures [43, 44]. Convergent validity refers to the consistency exhibited by multiple items in measuring the same construct. The criteria used for assessing convergent validity $[38,45,46]$ were as follows: (1) the reliability coefficients (Cronbach's alpha) should exceed 0.7, (2) the composite reliability (CR) coefficients for each latent construct should exceed 0.7 , and (3) the average variance extracted (AVE) for each latent construct should exceed 0.5 .

Table 3 lists the reliability indices and convergent validity scores of the constructs. The standardized item loadings ranged from 0.603 to 0.913 and were significant at 0.01 [38]. Cronbach's alpha coefficients ranged from
0.888 for discomfort to 0.948 for insecurity, indicating high internal consistency of the survey instrument (Table 3 ). As shown in Table 3, all values exceeded the recommended level of 0.7 , thereby reflecting the high robustness of the scale [38].

CR refers to a set of latent construct indicators that are consistent in their measurement; $\mathrm{CR}$ is also the degree to which a set of two or more construct indicators are consistent in their measurement [38]. The CR coefficients for all constructs ranged from 0.915 for discomfort to 0.965 for insecurity (Table 3), and thus, all were above the 0.7 benchmarks recommended by Fornell and Larcker [46]. The test for construct validity was conducted because this test is crucial for stabilizing the measure dimensionality during measure development [47].

Convergent and discriminant validity were evaluated by calculating the AVE for each factor in every model. Convergent validity is established when the shared variance accounts for at least $50 \%$ of the total variance. Discriminant validity refers to the degree to which measurements of a concept are distinct, implying that correlations among items on the same scale should be higher than those between items in different constructs. Discriminant validity is evident when the AVE for each construct exceeds the squared correlation between the construct in question and any other construct in the model [46]. All constructs exhibited AVE values between 0.545 for discomfort and 0.864 for insecurity (Table 3 ), and thus, all exceeded the 0.5 benchmarks recommended by Fornell and Larcker [46]. In 
TABLE 4: Estimation results for hypotheses.

\begin{tabular}{|c|c|c|c|c|c|c|}
\hline \multirow{2}{*}{ Construct } & \multicolumn{2}{|c|}{ Model 1} & \multicolumn{2}{|c|}{ Model 2} & \multicolumn{2}{|c|}{ Model 3} \\
\hline & $\beta$ & $t$-value & $\beta$ & $t$-value & $\beta$ & $t$-value \\
\hline Habit $\longrightarrow$ UI & $0.283^{* *}$ & 4.411 & $0.282^{* *}$ & 4.442 & $0.303^{* *}$ & 5.121 \\
\hline $\mathrm{PE} \longrightarrow \mathrm{UI}$ & $0.158^{* *}$ & 2.469 & $0.157^{* *}$ & 2.505 & $0.165^{* *}$ & 3.232 \\
\hline $\mathrm{EE} \longrightarrow \mathrm{UI}$ & 0.002 & 0.027 & 0.023 & 0.309 & -0.011 & 0.168 \\
\hline $\mathrm{SI} \longrightarrow \mathrm{UI}$ & 0.060 & 1.314 & 0.069 & 1.519 & 0.057 & 1.341 \\
\hline $\mathrm{FC} \longrightarrow \mathrm{UI}$ & $0.344^{* *}$ & 5.403 & $0.338^{* *}$ & 5.584 & $0.310^{* *}$ & 5.251 \\
\hline $\mathrm{PI} \longrightarrow \mathrm{UI}$ & $0.125^{* *}$ & 3.295 & $0.150^{* *}$ & 4.250 & $0.167^{* *}$ & 5.340 \\
\hline \multicolumn{7}{|l|}{ Moderator effect } \\
\hline e-Health literacy $\longrightarrow$ UI & & & $0.072^{* *}$ & 2.345 & $0.087^{* *}$ & 2.647 \\
\hline \multicolumn{7}{|l|}{ Interaction effect } \\
\hline PE X e-health literacy $\longrightarrow$ UI & & & & & $0.110 *$ & 1.796 \\
\hline EE X e-health literacy $\longrightarrow$ UI & & & & & 0.030 & 0.409 \\
\hline SI X e-health literacy $\longrightarrow$ UI & & & & & 0.003 & 0.055 \\
\hline FC X e-health literacy $\longrightarrow$ UI & & & & & 0.028 & 0.527 \\
\hline \multicolumn{7}{|l|}{$\overline{R^{2}}$} \\
\hline UI & 0.691 & 0.694 & 0.716 & & & \\
\hline
\end{tabular}

addition, this study also shows the DV values of all constructs in Table 3 . The results indicated that the DV of all constructs were greater than 1.0, which means that all constructs in this study had good level of discriminate validity [48]. Overall, the items demonstrated satisfactory convergent and discriminant validity.

3.2. Hypothesis Testing. To test our research hypotheses, we specified paths between constructs to build a structural model that matched the proposed relationships. Figure 2 shows the results of SEM estimation, including the standardized path coefficients for each hypothesized path in the model, significance based on the one-tailed $t$-tests, and amount of variance $\left(R^{2}\right)$. Standardized beta coefficients from the estimated structural model are reported in Table 4 alongside the associated $t$-values for each construct.

Regarding the components of the UTAUT2 model, habit, PE, and FCs exerted significant positive effects on UI (standardized beta coefficient $=0.303,0.165$, and 0.310 , resp.; $p<0.05)$. Therefore, Hypotheses 1, 2, and 5 were supported. By contrast, the constructs of EE and SI had negligible effects on UI (standardized beta coefficient $=-0.011$ and 0.057 , resp.; $p>0.05)$. Therefore, Hypotheses 3 and 4 were not supported. PI had a significant positive effect on UI (standardized beta coefficient $=0.167 ; p<0.05$ ). Therefore, Hypothesis 6 was supported. Moreover, e-health literacy had a significant positive effect on UI (standardized beta coefficient $=0.087 ; p<0.05)$ and the interaction effects of $\mathrm{PE}$ and e-health literacy (M1) on UI (standardized beta coefficient $=0.110 ; p<0.05)$, whereas $\mathrm{EE}$ and e-health literacy (M2), SI and e-health literacy (M3), and FCs and e-health literacy (M4) had only negligible effects on UI (standardized beta coefficient $=0.030,0.003$, and 0.028, resp.; $p>0.05$ ). Therefore, M1 was supported but M2, M3, and M4 were not supported. These constructs explained $71.6 \%$ of the variance in UI.

\section{Discussion}

In recent years, hospitals have developed medical apps (with functions such as registration assistance and waiting information) to provide a convenient medical environment to the public. Thus, the public's UI toward medical apps has become a crucial topic. This study combined the UTAUT2 model [9] with PI to propose a new framework for examining the UI of the public toward medical apps. No other study has empirically examined the moderating effect of e-health literacy on UI. Therefore, this study included e-health literacy as a moderating variable to explore whether individuals' e-health literacy levels affected their UI toward medical apps. The results revealed that the reliability, validity, path coefficient, and variance explained $\left(R^{2}\right.$ value) indicated favorable effectiveness of the model. The results could serve as a reference for suppliers of medical mobile app service systems to make system adjustments in order to enhance the UIs of users. In the research model proposed in this study, the dependent variables explained $71.6 \%$ of the variance $\left(R^{2}\right.$ value) of the overall model. The aforementioned data confirm that the theoretical framework proposed in this study was sufficient to explain the public's UI toward medical apps.

The empirical results indicated that EE and SI had no effect on UI. Because apps have a wide range of uses and are integrated into daily life, people use them frequently. Moreover, people are accustomed to using apps and understanding their advantages. The empirical results indicated that EE and SI exerted only negligible effects on UI. However, habit, PE, and FCs significantly affected UI. These results concurred with those of previous studies [11-18]. In addition, PI also significantly affected UI, which is consistent with previous studies $[26,27]$. Because many individuals are accustomed to using medical apps, the diverse information provided by medical apps enables individuals to quickly perform health-related tasks (e.g., registering at hospitals, obtaining waiting information, 
and researching medical conditions), understand medical information, and seek appropriate services. Furthermore, many individuals believe that medical apps enable access to vital medical information. Thus, habit, PE, and FCs considerably affected UI; in particular, FCs had a key effect on UI. Hospitals that aim to enhance the UI of the public toward medical apps are encouraged to provide health education and comprehensive and relevant medical information in their medical apps.

The e-health literacy of the public significantly affected their UI, and the interaction between PE and e-health literacy positively affected UI. When people are highly e-health literate, their understanding of medical apps results in favorable PE, which in turn enhances people's UI toward medical apps. For people with high e-health literacy, understanding that medical apps provide substantial medical knowledge and relevant information can simultaneously increase medical service efficiency and enhance the UI of such people toward medical apps.

\section{Conclusion}

This study proposed a causal model to explore the public's UI toward medical apps. For hospital managers, the importance of UI toward medical apps should be emphasized. The habit, PE, FCs, PI, and e-health literacy of the public had considerable positive effects on UI. Moreover, e-health literacy served as a moderator between $\mathrm{PE}$ and $\mathrm{BI}$. Therefore, enhancing the public's habit, PE, FCs, PI, and e-health literacy could considerably increase their UI toward medical apps. This work could serve as a basis for the validation of the used model and can be used to explain the adoption of technology in the medical area.

\section{Limitations and Future Research}

Although this study examined the factors that affect the UIs of individuals in Taoyuan toward medical apps, the study had several limitations. Several relevant topics in this field remain to be discussed. First, because the study participants were from the Taoyuan area, they were unrepresentative of the viewpoints of all Taiwanese people toward the topic in this study. Future studies could expand the research scope to include individuals from multiple regions in order to understand their differences. Second, this study conducted a questionnaire to understand the degree of perception and awareness of the situation among the respondents. The results can be compared and described only in the context of previous studies. Because this study was not sufficiently comprehensive, the UI and affecting factors of the public in relation to medical apps were impossible to understand. Therefore, in addition to data analysis, future studies are recommended to conduct in-depth interviews and qualitative research to accurately reflect the feelings of the public and generate comprehensive results. Finally, one potential limitation of this study was that we measured variables in only one-time frame by using a self-reported questionnaire; this suggests the potential for CMV. We tested for CMV by using the Harman one-factor test, which confirmed that all constructs exhibited approximately equal variance. This suggested that common method bias was not a problem in this study. Moreover, this study collected a considerable amount of data and recruited a large sample to circumvent the problem of CMV.

\section{Data Availability}

The data used to support the findings of this study are available from the corresponding author upon request.

\section{Conflicts of Interest}

The authors declare that there are no conflicts of interest regarding the publication of this paper.

\section{Acknowledgments}

The authors acknowledge the Taoyuan Armed Forces General Hospital of Taiwan for financially supporting this research under contract Taoyuan Armed Forces General Hospital: 10621.

\section{References}

[1] T. Heart and E. Kalderon, "Older adults: are they ready to adopt health-related ICT?" International Journal of Medical Informatics, vol. 82, no. 11, pp. e209-e231, 2013.

[2] M. T. Simsim, "Internet usage and user preferences in Saudi Arabia," Journal of King Saud University - Engineering Sciences, vol. 23, no. 2, pp. 101-107, 2011.

[3] N. Wagner, K. Hassanein, and M. Head, "Computer use by older adults: a multi-disciplinary review," Computers in Human Behavior, vol. 26, no. 5, pp. 870-882, 2010.

[4] T. Tsu Wei, G. Marthandan, A. Yee-Loong Chong, K. B. Ooi, and S. Arumugam, "What drives Malaysian m-commerce adoption? An empirical analysis," Industrial Management \& Data Systems, vol. 109, no. 3, pp. 370-388, 2009.

[5] Y.-F. Kuo and S.-N. Yen, "Towards an understanding of the behavioral intention to use $3 \mathrm{G}$ mobile value-added services," Computers in Human Behavior, vol. 25, no. 1, pp. 103-110, 2009.

[6] U. Varshney, R. J. Vetter, and R. Kalakota, "Mobile commerce: a new frontier," Computer, vol. 33, no. 10, pp. 32-38, 2000.

[7] E. Saidi, "Mobile opportunities, mobile problems: assessing mobile commerce implementation issues in Malawi," The Journal of Internet Banking and Commerce, vol. 14, no. 1, pp. 1-10, 1970.

[8] P. J. B. Tan, "Applying the UTAUT to understand factors affecting the use of English e-learning websites in Taiwan," Sage Open, vol. 3, no. 4, pp. 1-12, 2013.

[9] P. J. B. Tan, "Students' adoptions and attitudes towards electronic placement tests: a UTAUT analysis," American Journal of Computer Technology and Application, vol. 1, no. 1, pp. 14-23, 2013.

[10] V. Venkatesh, M. G. Morris, G. B. Davis, and F. D. Davis, "User acceptance of information technology: toward a unified view,” MIS Quarterly, vol. 27, no. 3, pp. 425-478, 2003.

[11] V. Venkatesh, J. L. Thong, and X. Xu, "Consumer acceptance and use of information technology: extending the unified theory of acceptance and use of technology," MIS Quarterly, vol. 36, no. 1, pp. 157-178, 2012. 
[12] M. Z. Alam, M. R. Hoque, W. Hu, and Z. Barua, "Factors influencing the adoption of mHealth services in a developing country: a patient-centric study," International Journal of Information Management, vol. 50, pp. 128-143, 2020.

[13] A. A. Alalwan, Y. K. Dwivedi, and N. P. Rana, "Factors influencing adoption of mobile banking by Jordanian bank customers: extending UTAUT2 with trust," International Journal of Information Management, vol. 37, no. 3, pp. 99-110, 2017.

[14] Á. Herrero, H. San Martín, and M. d. M. Garcia-De los Salmones, "Explaining the adoption of social networks sites for sharing user-generated content: a revision of the UTAUT2," Computers in Human Behavior, vol. 71, pp. 209217, 2017.

[15] I. M. Macedo, "Predicting the acceptance and use of information and communication technology by older adults: an empirical examination of the revised UTAUT2," Computers in Human Behavior, vol. 75, pp. 935-948, 2017.

[16] Z. Sheikh, T. Islam, S. Rana, Z. Hameed, and U. Saeed, "Acceptance of social commerce framework in Saudi Arabia," Telematics and Informatics, vol. 34, no. 8, pp. 1693-1708, 2017.

[17] T. Escobar-Rodríguez and E. Carvajal-Trujillo, "Online purchasing tickets for low cost carriers: an application of the unified theory of acceptance and use of technology (UTAUT) model," Tourism Management, vol. 43, pp. 70-88, 2014.

[18] M. E. Rogers and F. F. Shoemaker, Communication of Innovation: A Cross-Culture Approach, Free Press, New York, NY, USA, 1971.

[19] M. Z. Alam, W. Hu, M. A. Kaium, M. R. Hoque, and M. M. D. Alam, "Understanding the determinants of mHealth apps adoption in Bangladesh: a SEM-Neural network approach," Technology in Society, vol. 61, p. 101255, 2020.

[20] E. M. Rogers, Diffusion of Innovations, Free Press, New York, NY, USA, 5th edition, 2003.

[21] R. Agarwal and J. Prasad, "A conceptual and operational definition of personal innovativeness in the domain of information technology," Information Systems Research, vol. 9, no. 2, pp. 204-215, 1998.

[22] S.-b. Park and N. Chung, "Mediating roles of self-presentation desire in online game community commitment and trust behavior of massive multiplayer online role-playing games," Computers in Human Behavior, vol. 27, no. 6, pp. 2372-2379, 2011.

[23] D. F. Midgley and G. R. Dowling, "Innovativeness: the concept and its measurement," Journal of Consumer Research, vol. 4, no. 4, pp. 229-242, 1978.

[24] M. Limayern, M. Khalifa, and A. Frini, "What makes consumers shop via internet? A longitudinal study of online shopping," IEEE Transactions on Systems, Man and Cybernetics, Part A: Systems and Humans, vol. 30, no. 4, pp. 421432, 2000.

[25] C.-H. Wong, G. W.-H. Tan, B.-I. Tan, and K.-B. Ooi, "Mobile advertising: the changing landscape of the advertising industry," Telematics and Informatics, vol. 32, no. 4, pp. 720-734, 2015.

[26] G. W.-H. Tan, K.-B. Ooi, S.-C. Chong, and T.-S. Hew, "NFC mobile credit card: the next frontier of mobile payment?" Telematics and Informatics, vol. 31, no. 2, pp. 292-307, 2014.

[27] K. A. Al-Busaidi, "An empirical investigation linking learners' adoption of blended learning to their intention of full e-learning," Behaviour \& Information Technology, vol. 32, no. 11, pp. 1168-1176, 2013.

[28] V. Sánchez, N. Muñoz-Fernández, and R. Ortega-Ruíz, “"Cyberdating Q_A": an instrument to assess the quality of adolescent dating relationships in social networks," Computers in Human Behavior, vol. 48, pp. 78-86, 2015.

[29] I. Pantic, "Online social networking and mental health," Cyberpsychology, Behavior, and Social Networking, vol. 17, no. 10, pp. 652-657, 2014.

[30] C.-H. Lai and H.-L. Gwung, "The effect of gender and Internet usage on physical and cyber interpersonal relationships," Computers \& Education, vol. 69, pp. 303-309, 2013.

[31] S. R. Cotten and S. S. Gupta, "Characteristics of online and offline health information seekers and factors that discriminate between them," Social Science \& Medicine, vol. 59, no. 9, pp. 1795-1806, 2004.

[32] C. D. Norman and H. A. Skinner, "eHealth literacy: essential skills for consumer health in a networked world," Journal of Medical Internet Research, vol. 8, no. 2, p. 9, 2006.

[33] C. D. Norman, "The web of influence: evaluating the impact of internet interventions on adolescent smoking cessation \& ehaelth literacy," Unpublished Doctoral Dissertation, University of Toronto, Toronto, Canada, 2005.

[34] I. Ajzen, "The theory of planned behavior," Organizational Behavior and Human Decision Processes, vol. 50, no. 2, pp. 179-211, 1991.

[35] I. Ajzen, "The theory of planned behavior," Handbook of Theories of Social Psychology, vol. 1, no. 1, pp. 438-459, 2011.

[36] S. B. MacKenzie, P. M. Podsakoff, and N. P. Podsakoff, "Construct measurement and validation procedures in MIS and behavioral research: integrating new and existing techniques," MIS Quarterly, vol. 35, no. 2, pp. 293-334, 2011.

[37] R. F. DeVellis, Scale Development: Theory and Applications, Sage Publications, Thousand Oaks, CA, USA, 2nd edition, 2003.

[38] F. Hair Jr., W. C. Black, B. J. Babin, and R. E. Anderson, Multivariate Data Analysis: A Global Perspective, Macmillan, New York, NY, USA, 7th edition, 2010.

[39] K. G. Jöreskog and D. Sörbom, LISREL 8.72: A Guide to the Program and Applications, Scientific Software International, Inc., Chicago, IL, USA, 3rd edition, 2005.

[40] W. W. Chin, "The partial least squares approach to structural equation Modeling," in Modern Business Research Methods, G. A. Marcoulides and Mahwah, Eds., pp. 295-336, Lawrence Erlbaum Associates, Mahwah, NJ, USA, 1998.

[41] W. W. Chin, B. L. Marcolin, and P. R. Newsted, "A partial least squares latent variable modeling approach for measuring interaction effects: results from a Monte Carlo simulation study and an electronic-mail emotion/adoption study," Information Systems Research, vol. 14, no. 2, pp. 189-217, 2003.

[42] P. M. Podsakoff, S. B. MacKenzie, J.-Y. Lee, and N. P. Podsakoff, "Common method biases in behavioral research: a critical review of the literature and recommended remedies," Journal of Applied Psychology, vol. 88, no. 5, p. 879, 2003.

[43] H.-J. Chen, “Linking employees' e-learning system use to their overall job outcomes: an empirical study based on the IS success model," Computers \& Education, vol. 55, no. 4, pp. 1628-1639, 2010.

[44] S. Y. X. Komiak and I. Benbasat, "The effects of personalization and familiarity on trust and adoption of recommendation agents," MIS Quarterly, vol. 30, no. 4, pp. 941-960, 2006.

[45] R. P. Bagozzi and Y. Yi, "Specification, evaluation, and interpretation of structural equation models," Journal of the Academy of Marketing Science, vol. 40, no. 1, pp. 8-34, 2012. 
[46] C. Fornell and D. F. Larcker, "Evaluating structural equation models with unobservable variables and measurement error," Journal of Marketing Research, vol. 18, no. 1, pp. 39-50, 1981.

[47] R. F. DeVellis, Scale Development: Theory and Applications, Vol. 26, Sage publications, Thousand Oaks, CA, USA, 2016.

[48] J. F. Hair Jr., G. T. M. Hult, C. Ringle, and M. Sarstedt, A Primer on Partial Least Squares Structural Equation Modeling (PLS-SEM), Sage Publications, Thousand Oaks, CA, USA, 2016. 